\title{
PLIOCENE SCALLOP GROWTH LINES: POTENTIAL FOR ENVIRONMENTAL RECONSTRUCTION AND POPULATION DYNAMICS
}

\author{
CLARK*, George R., II; ARCHER, Allen W., Dept. of Geology, Thompson Hall, Kansas \\ State Univ., Manhattan, KS 66506-3201 U.S.A.
}

Prominent growth ridges on the shell of the modern scallop Pecten diegensis are known to form with a daily periodicity. Pecten stearnsii, its direct ancestor, has the same growth ridges and would be expected to form them at the same rate.

Pecten stearnsii specimens collected from the Pliocene Imperial Formation near San Filipe, Baja California, Mexico, have repetitive variations in the spacing of their growth ridges. Harmonic analysis of these variations found three tidal periodicities to be present, tropic (13.7 days), synodic (14.8 days), and anomalistic (27.6 days). This observation also served to confirm the daily nature of the growth ridges.

Tidal patterns at various locations within the present-day Gulf of California are dominated to various degrees by synodic and tropic periodicities. Comparisons of the growth-line records to modern tidal records by cross-correlation found a good match with a tidal station south of the collecting site, where the tropic periodicity dominates but the synodic periodicity is still important.

An important aspect of this match is that a graph of cross-correlations at all possible overlaps shows a cycle of good correlations, with a period of six months between peaks. As this is a reflection of the resonance between tropic and synodic periodicities, the peaks would occur at the same times of year in the Pliocene as today. This makes it possible to relate each specimen's growth record to the calendar, although two alternate interpretations, six months apart, would exist.

Two possible relationships would be of interest. First, if all the specimens had died at the same time of year it could mean a catastrophe, such as a severe storm. This was not the case, which is in itself a useful observation. Second, if all the specimens began their growth line record at the same time of year, it would suggest specific seasons for spawning and for spatfall. Here the evidence was more supportive; most specimens began forming growth ridges in either late March or late September, with perhaps a month's growth prior to the first growth ridge.

If isotopic paleotemperature analysis can be applied to these shells, or to others with similar characteristics, new levels of resolution in both environmental reconstruction and paleopopulation analysis may be achieved. 